\title{
Desenvolvimento, Direitos Humanos e Corrupção: Correlações Entre IDH e IPC no Caso Brasileiro
}

\author{
Analissa Barros Pinheiro \\ Mestre em Direito e Instituições do Sistema de Justiça pela Universidade Federal do Maranhão. Bacharel em Direito pela Ufma. \\ Assessora Jurídica da Universidade Estadual do Maranhão e professora da Universidade Ceuma. http://lattes.cnpq.br/3944455170235725. \\ https://orcid.org/0000-0002-3994-8179. analissa.pinheiro@gmail.com

\section{Fernanda Cristina de Oliveira Franco} \\ Professora-adjunta do curso de Direito da Ufob. Doutora e mestre em Ciências Jurídicas, com ênfase em Direitos Humanos \\ e Desenvolvimento pelo Programa de Pós-Graduação em Ciências Jurídicas da UFPB. Bacharel em Direito pela Faculdade de Direito \\ da Universidade de São Paulo. http://lattes.cnpq.br/9298023582118297. https://orcid.org/0000-0002-4046-1181. \\ ffranco.cristina@gmail.com
}

O exercício do desenvolvimento como um direito é plataforma política e normativa que vem sendo discutida há décadas em âmbito internacional. O irromper global de medidas anticorrupção não deixou de entrar em diálogo com esse debate. O resultado é o reconhecimento, em vários instrumentos internacionais, dos efeitos adversos da corrupção ao desenvolvimento, bem como do advento das abordagens dos direitos humanos à corrupção, que a caracterizam como prática que viola direitos humanos e obstaculiza o exercício do direito ao desenvolvimento. O presente estudo ressalta as relações entre desenvolvimento, direitos humanos e corrupção, esmiuçando esta correlação a partir da análise conjunta entre o IDH e o IPC. O contexto brasileiro de anos recentes serve como parâmetro para investigar em que medida ações anticorrupção garantem melhorias nos índices de desenvolvimento e de efetivação dos direitos humanos e vice-versa.

Palavras-chave: Corrupção. IDH. IPC. Direito ao desenvolvimento. Direitos humanos.

\section{DEVELOPMENT, HUMAN RIGHTS AND CORRUPTION: CORRELATIONS BETWEEN HDI AND CPI IN THE BRAZILIAN CASE}

\section{ABSTRACT}

The exercise of development as a right is a political and normative platform that has been discussed for decades in the international arena. The global eruption of anti-corruption measures did not fail to touch this debate. The result is the recognition by various international instruments of the adverse effects of corruption on development, and the emergence of human rights approaches to corruption that reaffirm it as a practice that violates human rights and undermines the exercise of the right to development. The present study high lights the relationship among development, human rights and corruption, breaking down this correlation based on the joint analysis between the HDI and the CPI. The recent Brazilian context is taken as a parameter to investigate to what extent anti-corruption actions can effectively guarantee better development and human rights effectiveness and vice versa. Keywords: Corruption. HDI. PCI. Right to development. Human rights.

1 Introdução. 2 Abordagens dos direitos humanos à corrupção. 3 Os impactos da corrupção no desenvolvimento e vice-versa. 3.1 Exercício do Direito ao Desenvolvimento (Dad) diante da corrupção. 3.2 A relação entre desenvolvimento e corrupção: análise comparada entre o IDH e o IPC. 3.3 A relação entre IDH e IPC no contexto brasileiro recente. 4 Considerações finais. 5 Referências. 


\section{Humanos e \\ Democracia}

\section{INTRODUÇÃO}

A ideia de progresso, de evolução, de trajetória linear ascendente sempre permeou o imaginário humano de alguma forma. O desenvolvimento é uma dessas concepções que surge atrelada aos anseios de crescimento, incremento, melhorias. Num primeiro momento, identificou-se com as metas de crescimento econômico. No contexto descolonial do século 20, foi reivindicado por países do Terceiro Mundo como direito fundamental dos povos. 0 fato é que as discussões sobre os desafios de efetivação do desenvolvimento como um direito humano, o chamado Direito ao Desenvolvimento (Dad), tem sido desde então objeto de inúmeras discussões em âmbito internacional, em meio a muitos obstáculos e poucos avanços. Destaque-se o desenvolvimento como objeto central das relações internacionais e do próprio Direito Internacional.

A corrupção, por sua vez, é prática antiga, ainda que seu irromper em âmbito global seja relativamente recente. Já chegou a ser tolerada como função benéfica e necessária ao processo de desenvolvimento econômico e político, visto que contribuiria para a superação da rigidez democrática e das normas tradicionais (FILGUEIRAS, 2004, p. 136). Nas últimas décadas, entretanto, passou a ser vista como fenômeno indesejável, disseminado e de difícil enfrentamento, cujo combate exigiria a atuação conjunta entre Estados, posto que suas formas e consequências não se restringem aos limites territoriais nacionais.

Diante da internacionalização da corrupção, ganham força as abordagens dos direitos humanos à corrupção (human rights-based approaches to corruption), que expandem o tradicional enfoque até então restrito ao âmbito das transações econômicas para visibilizar os efeitos que acarreta na vida das pessoas e no exercício de seus direitos fundamentais, incluindo a discussão sobre o exercício do desenvolvimento como um direito.

As tentativas para coibir a prática da corrupção passaram a ser foco de iniciativas internacionais conjuntas, inaugurando nova fase de enfrentamento global do tema. Na prática, apurou-se que todos os anos cerca de US\$ 1 trilhão são pagos em subornos em processos envolvendo corrupção e são apropriados pela corrupção aproximadamente US\$ 2,6 trilhões, o equivalente a mais de $5 \%$ do PIB global. ${ }^{1}$ Os recursos gastos com a corrupção acabam não atingindo os fins públicos aos quais se destinariam originalmente, o que é um entrave para a promoção do desenvolvimento.

Diante desse contexto, o presente estudo propõe-se a analisar a inter-relação entre desenvolvimento, direitos humanos e corrupção de forma a entender em que medida interagem e se afetam mutuamente. Para tanto, a primeira parte caracteriza as abordagens dos direitos humanos à corrupção, que inovam ao complexificar o tradicional enfoque econômico sobre o tema, afirmando a corrupção como prática contrária à efetivação do desenvolvimento e dos direitos humanos. A segunda parte analisa os impactos da corrupção sobre o exercício do direito ao desenvolvimento, investigando em especial a relação entre dois indicadores: o IDH

TRANSPARENCY INTERNATIONAL. Business Case Against Corruption. 2016. Disponível em: http://www.weforum.org/pdf/ paci/BusinessCaseAgainstCorruption.pdf. Acesso em: 3 out. 2017. 
(Índice de Desenvolvimento Humano) $)^{2}$ e o IPC (Índice de Percepção da Corrupção). ${ }^{3}$ Com base nestes dois índices, enfoca particularmente o caso brasileiro para considerar em que medida ações anticorrupção garantem melhores índices de desenvolvimento e de efetivação dos direitos humanos e vice-versa.

\section{ABORDAGENS DOS DIREITOS HUMANOS À CORRUPÇÃO}

Internacionalmente, um dos resultados do tratamento conjunto das relações entre corrupção e direitos humanos se traduz na normativa internacional que centra a corrupção como objeto de tratados multilaterais, os quais buscam meios efetivos de tipificar, isolar, prevenir e punir essa prática. ${ }^{4}$ Tais instrumentos normativos refletem novas formas de se mirar a corrupção, caracterizando-a não apenas como um ilícito, mas também como uma agressão à democracia, à solidariedade, à justiça, bem como aos direitos humanos. Tais abordagens garantem padrões internacionais no combate à corrupção, obrigando os Estados nacionais a desenvolverem políticas e práticas anticorrupção (BACIO-TERRACINO, 2010, p. 245).

O amplo processo de internacionalização da normativa, direcionado a estabelecer as bases jurídicas da identificação e combate à corrupção, foi a base para o surgimento de documentos internacionais sobre o tema, com destaque para a Convenção das Nações Unidas Contra a Corrupção (2003), ${ }^{5}$ que reconhece em seu preâmbulo os malefícios ocasionados pela corrupção à instabilidade, insegurança, instituições e à democracia, além de minar os esforços de promoção do desenvolvimento humano. ${ }^{6}$

Ainda no âmbito da normativa internacional, cite-se a consideração do Conselho Europeu, que define o fenômeno da corrupção como uma ameaça aos direitos humanos, na medida em que mina o Estado de Direito, a democracia, e cerceia os Estados a promoverem um bom governo para seus respectivos cidadãos (KOECHLIN; CARMONA, 2009, p. 150). Nesse sentido, reconhecem que a corrupção reduz a capacidade do governo de respeitar, proteger e

\footnotetext{
O Índice de Desenvolvimento Humano (IDH) é uma medida importante concebida pela ONU (Organização das Nações Unidas) para avaliar a qualidade de vida e o desenvolvimento econômico de uma população. Anualmente é elaborado o Relatório de Desenvolvimento Humano (RDH) pelo Programa das Nações Unidas para o Desenvolvimento (Pnud) com base em três critérios (saúde, educação e renda) que são medidos pelas variáveis: expectativa de vida ao nascer; média de anos de estudo (adultos) e anos esperados de escolaridade (crianças); Renda Nacional Bruta (RNB) com base na Paridade de Poder de Compra (PPC) por habitante. O IDH varia entre 0 (nenhum desenvolvimento humano) e 1 (desenvolvimento humano total), revelando que quanto maior a proximidade de 1 , mais desenvolvido é o país.

3 Elaborado pela Organização Não Governamental Transparência Internacional, o Índice de Percepção da Corrupção tem o objetivo de mensurar os níveis de corrupção no mundo. Constitui-se em um índice resultante de diferentes estudos e pesquisas acerca dos níveis de percepção da corrupção no setor público de diversos países.

4 Cite-se a Convenção Interamericana contra a Corrupção da OEA (1996); Convenção sobre o Combate da Corrupção de Funcionários Públicos Estrangeiros em Transações Comerciais Internacionais da Organização para a Cooperação Econômica e o Desenvolvimento da OCDE (1997); Convenção das Nações Unidas contra a Corrupção (2003). O Brasil é signatário dos três instrumentos.

A United Nations Convention Against Corruption (Convenção das Nações Unidas contra a Corrupção) constitui-se em uma convenção que visa a promover e fortalecer as medidas para prevenir e combater mais eficaz e eficientemente a corrupção. É o maior texto juridicamente vinculante de luta contra a corrupção. A referida Convenção foi assinada em 9 de dezembro de 2003, na cidade de Mérida, no México. Em virtude da assinatura desta Convenção, no dia 9 de dezembro comemora-se o Dia Internacional de Luta Contra Corrupção em todo o mundo.

${ }^{6}$ ONU. Convention dês Nations Unies Contre La corruption, DOC.A/58/422, adotada em 14 de dezembro de 2003.
} 


\section{Humanos e}

Democracia

efetivar seus compromissos assumidos em termos de direitos humanos, além de reduzir a capacidade dos governos de financiar serviços básicos, dificultando que os cidadãos encontrem adequados meios de vida, o que resulta em violações aos direitos humanos.

As abordagens dos direitos humanos em relação à corrupção, contudo, não se restringem aos aspectos da normativa internacional. Além da normativa internacional há outras vinculações possíveis entre corrupção e direitos humanos. Uma delas aponta que ambos são discursos relevantes nas discussões sobre a legitimidade do poder do Estado e, mais recentemente, também sobre a legitimidade da atuação do poder das empresas/corporações. ${ }^{7}$

Vieira e Varella (2014, p. 56) identificam três relações causais entre corrupção e direitos humanos, reconhecendo ser a corrupção uma possível i) causa direta; ii) indireta ou iii) remota para as violações de direitos humanos. No primeiro caso, a corrupção é diretamente ligada a uma violação de direito humano quando, por exemplo, um ato corrupto é deliberadamente utilizado para violação deste direito, como no caso de desvios de recursos destinados à merenda escolar. No segundo caso, de forma indireta, a corrupção pode violar direitos humanos quando integra uma série de ações que levam a uma violação de direitos humanos, por exemplo, quando setores governamentais aceitam receber contêineres com lixo contaminado em troca de suborno. Por fim, existe ainda a forma remota, quando a corrupção constitui-se em um dos fatores que levam à violação dos direitos humanos, como quando em um processo eleitoral a corrupção na contagem dos votos aviva preocupações acerca da precisão do resultado, decorrendo disso agitações sociais e protestos. A repressão a tais protestos poderá ocasionar violações de direitos humanos.

No âmbito estatal, tanto a corrupção como os direitos humanos se relacionam ao quanto um determinado Estado se preocupa, no primeiro caso, em proteger a primazia do interesse público sobre o privado e, no segundo, a primazia dos direitos humanos de seus cidadãos. Dessa forma, mesmo sendo possível traçar diferenças entre os dois campos, evidencia-se uma relação direta e inversamente proporcional entre eles: isto é, onde há maior grau de corrupção, verifica-se menor efetivação dos direitos humanos (RAJAGOPAL, 1999, p. 498), ou seja, baixos índices de corrupção são necessários para a maior proteção dos direitos humanos e vice-versa.

Por essa razão, o maior interesse não é tanto em relação ao fenômeno da corrupção em si, mas sim no quanto ele afeta negativamente o exercício dos direitos humanos, devendo, por isso manter-se em baixos níveis para que se assegure alto nível de proteção dos direitos humanos.

Em todos os cenários a corrupção se constitui como antagonista social, política e econômica, tendo por consequência direta e indireta violações de direitos humanos. Nesse sentido, pontua Gebeye (2012, p. 89) que: "[a] implementação dos direitos humanos pode contribuir para a prevenção da corrupção, porque os direitos humanos abordam os abusos de poder e a corrupção é essencialmente um abuso de poder".

Vide as discussões sobre Empresas e Direitos Humanos e a tendência de responsabilização de atores não estatais pela violação destes. 
Tanto o discurso da corrupção quanto o dos direitos humanos preocupam-se com o tema do desenvolvimento, razão pela qual os economistas não mais argumentam que a corrupção é necessária para a promoção do desenvolvimento - como já o fizeram explicitamente - como igualmente reconhecem que a violação dos direitos humanos também não é mais condizente/intrínseca à promoção do desenvolvimento (RAJAGOPAL, 1999, p. 500). Em suma, a prevenção e o enfrentamento da corrupção são fundamentais para a promoção dos direitos humanos, e, de forma simultânea, a garantia dos direitos humanos pode significar a redução dos casos de corrupção.

Essa constatação, contudo, não pode desconsiderar que tanto a prática da corrupção como a da violação de direitos humanos têm servido como critério de (des)legitimidade de um determinado tipo de Estado ou governo (RAJAGOPAL, 1999, p. 504), havendo inclusive inúmeros exemplos de como o discurso da corrupção, e/ou o discurso dos direitos humanos são/foram usados para (des)legitimar ou impulsionar a destituição de um governo ou de um Estado. O discurso anticorrupção, dessa maneira, não dispensa considerações sob perspectivas críticas e históricas.

\section{OS IMPACTOS DA CORRUPÇÃO NO DESENVOLVIMENTO E VICE-VERSA}

Por ser um fenômeno que se reflete em diversas esferas (sociais, econômicas, políticas, jurídicas, etc.) a corrupção acaba por impactar o desenvolvimento de um determinado Estado. Os tópicos a seguir desenvolvem essa ideia, trazendo para a discussão algumas das relações estabelecidas entre ambos.

\subsection{Exercício do Direito ao Desenvolvimento (Dad) diante da Corrupção}

O impacto da corrupção no exercício do Dad pode ser investigado por meio do mapeamento dos recursos que deveriam ser investidos na promoção do desenvolvimento como um direito. Trata-se o Direito ao Desenvolvimento (Dad) de um direito humano cuja instituição requer a efetivação de uma série de outros direitos, como educação, saúde, moradia, liberdades, sendo por isso considerado um direito-síntese, ou um direito-plataforma.

O Dad é um direito humano de vertente jurídica emancipatória, cuja titularidade é endereçada aos povos e coletividades e caracterizado como um conjunto de ações de responsabilidade de Estados e agentes econômicos para garantir o equilíbrio da balança global da distribuição e usufruto dos recursos (FRANCO, 2013, p. 139).

Nesse sentido, a questão da disponibilidade dos recursos, bem como da capacidade de acessá-los e deles dispor livremente é aspecto relevante para o exercício desse direito. De fato, sua reivindicação surge historicamente da tentativa de assegurar que os recursos disponíveis fossem revertidos em benefício de uma ampla maioria de pessoas do Terceiro Mundo.

Em termos do desenvolvimento, a corrupção mostra-se como um dos problemas para o acesso equitativo aos bens e serviços, uma vez que promove a alocação indevida de recursos, desviados de seus verdadeiros fins. É por isso considerada um dos maiores obstáculos ao desenvolvimento (KUMAR, 2003, p. 33). 


\section{Democracia}

Nos países em desenvolvimento, de acordo com o Programa de Desenvolvimento das Nações Unidas (PNUD), os recursos perdidos pela corrupção são dez vezes maiores do que aqueles remetidos à assistência oficial ao desenvolvimento (2011, p. 204).

A corrupção tem assim impacto contrário à promoção do desenvolvimento, na medida em que subtrai ilicitamente, para fins privados, os recursos que deveriam ser destinados à melhoria da qualidade de vida das pessoas. Com base nessa relação, inclusive foi delineado um direito fundamental a um serviço livre de corrupção (KUMAR, 2003).

Segundo Tanzi e Davoodi (1997, p. 59), a corrupção está diretamente correlacionada com a baixa qualidade das infraestruturas públicas, o aumento do investimento público e a diminuição da receita governamental. Segundo esses autores, quando faltam controle e fiscalização nas instituições, as decisões sobre investimento público ficam distorcidas, facilitando com que quanto maior o volume de recursos disponível maior pode ser o montante desviado.

Gupta et al. (2002, p. 31) afirmam que a corrupção afeta a desigualdade de renda e a pobreza e, segundo eles, existem vários canais pelos quais isso pode acontecer além do crescimento econômico. Observam que corrupção conduz à pobreza, pois o impacto negativo no crescimento provocado pela corrupção conduz a um nível de pobreza maior. Al-Marhubi (2000, p. 200) ressalta que altos níveis de corrupção estão associados ao aumento de inflação. Segundo o autor, isso ocorre porque a corrupção contribui para o aumento de déficits fiscais que pressionam a inflação.

Constata-se, assim, que a corrupção utiliza os recursos que deveriam estar disponíveis para garantir a promoção e o exercício do Dad para outros fins, afetando dessa forma diretamente as possibilidades de efetivação desse direito.

\subsection{A relação entre desenvolvimento e corrupção: análise comparada entre o IDH e o IPC}

Como forma de analisar concretamente as relações entre corrupção e desenvolvimento, oportuno considerar dois índices que auxiliam a entender como se dá essa interação. As correlações entre corrupção e desenvolvimento são amparadas por experimentos de cálculo do grau de corrupção, do volume dos desvios e do custo que o fenômeno traz para a economia, a sociedade e a credibilidade das instituições (SPECK, 2000).

À semelhança da medição do desenvolvimento por meio do Índice de Desenvolvimento Humano (IDH), avanços têm sido feitos na criação de um índice que investigue o grau de ocorrência da corrupção nos diversos países, normalmente utilizando aspectos subjetivos de percepção. Os elementos do índice serviram para consolidar hipóteses sobre o impacto da corrupção no desenvolvimento de um país (DOIG; RILEY, 2002, p. 46).

Abre-se parênteses para considerar as dificuldades de mensuração da corrupção, vez que as práticas corruptas são ilícitas e ocorrem de forma velada, impedindo uma medição objetiva. Ademais, se por um lado o advento do IDH conseguiu elaborar parâmetros internacionais para mensurar o desenvolvimento, uma questão de importância fundamental para o estudo da corrupção permanece sendo o da criação de um índice que viabilize sua mensuração internacionalmente. 
Como observado por Jain (2001, p. 120) e Mauro (2002, p. 53), o problema em medir a corrupção está na própria natureza de clandestinidade da prática, dado que o ambiente de ilegalidade no qual normalmente se reproduz faz com que ela não possa ser medida por meio de estatísticas oficiais ou de perguntas diretas sobre o envolvimento de pessoas em atos corruptos. Além disso, não se tem ao certo em que medida os aspectos culturais influenciam na prática ou na tolerância da corrupção.

Importante sistematizar que dos anos 70 até hoje é possível visualizar três gerações de estudos voltados a mensurar empiricamente a corrupção com base nas pesquisas de opinião. A primeira referiu-se à investigação das diferentes visões da corrupção e partiu do pressuposto de que os distintos modelos de conceituação do fenômeno representavam um problema. Diante disso, a saída mais corriqueira foi identificar a corrupção a partir de uma definição próxima àquela do Código Penal (MAURO, 2002, p. 24).

A segunda voltou-se à identificação dos riscos de investimento. Iniciou-se a partir dos anos 80, quando empresas de avaliação de riscos de investimento incluíram sucessivamente o item "corrupção" em suas análises dos países. Para avaliar instituições e normas, assim como a cultura e as práticas políticas relevantes para o investimento, os dados levantados incluem questões referentes à fragmentação do sistema partidário, a conflitos religiosos ou étnicos e à aceitação das normas constitucionais pelos vários atores políticos.

A terceira busca ferramentas para a intervenção e a reforma (MAURO, 2002, p. 29). O objetivo, aqui, segundo Kaufmann, Prahan e Ryterman (1998, p. 12), não é somente melhorar a qualidade dos números, mas redirecionar as análises, para instigar, orientar e monitorar políticas de reformas institucionais.

Uma das iniciativas de maior impacto nessa área foi a integração de informações contidas em diferentes indicadores em um único índice, avaliando-se especificamente a questão da corrupção em vários países, o que resultou no Índice de Percepção da Corrupção - IPC (Corruption Perceptions Index), o principal e mais conhecido índice internacional utilizado na atualidade para medir a corrupção pública (KAUFMANN; PRAHAN; RYTERMAN 1998, p. 11), aplicado pela Organização Não Governamental Transparência Internacional - TI. ${ }^{8}$

A organização TI teve grande influência tanto na compreensão da corrupção - segundo a organização, corrupção é o abuso de poder para obtenção de ganhos privados ilegítimos e sua ocorrência se dá tanto no setor público quanto no privado (TRANSPARENCY INTERNATIONAL, 2016a) - como especialmente no aumento da luta contra a corrupção na arena internacional, marcada por uma abordagem que fortalece articulações nacionais, regionais e globais, envolvendo Estados, instituições internacionais, sociedade civil e o setor privado.

O IPC classifica os países e territórios de acordo com níveis percebidos de corrupção no setor público. É composto por inúmeras avaliações e pesquisas de opinião promovidas por instituições respeitadas e reflete o entendimento de observadores de todo o mundo, inclusive

\footnotetext{
A Transparência Internacional (TI) é uma Organização Não Governamental que busca o enfrentamento da corrupção, analisando o fenômeno sob diversas perspectivas. A TI trabalha em conjunto com governos, empresas e cidadãos para acabar com o abuso de poder, o suborno e as negociações secretas. Ainda possui uma capacidade de pesquisa mundialmente reconhecida e um amplo conjunto de ferramentas e soluções de combate à corrupção. Link da Organização: https://transparenciainternacional.org.br
} 


\section{Humanos e \\ Democracia}

especialistas que vivem e trabalham nos locais avaliados. Concentra-se na corrupção praticada por funcionários públicos e políticos e sua fonte de dados decorre de questões como subornos, pagamentos de propinas em contratações públicas, desvios de recursos públicos, entre outras perguntas que verificam esforços e efetividade das medidas anticorrupção pelo setor público (TRANSPARENCY INTERNATIONAL, 2016b).

O IPC classifica 180 países e territórios por seus níveis percebidos de corrupção no setor público de acordo com especialistas e empresários e usa uma escala de 0 a 100, em que 0 é altamente corrupto e 100 muito livre de corrupção. No ano de 2017 o índice constatou que mais de dois terços dos países pontuaram abaixo de 50, com uma pontuação média de 43 (TRANSPARENCY INTERNATIONAL, 2017, p. 45), o que mostra o quanto a corrupção é uma prática disseminada pelo mundo.

A TI explicita que a corrupção sistêmica e a desigualdade social reforçam-se uma à outra (TRANSPARENCY INTERNATIONAL, 2016b, p. 58). De fato, pesquisas anteriores realizadas por You e Khagram (2005, p. 136-137) demonstram que quanto mais desigual for uma sociedade, maiores serão seus indicadores de corrupção. Em outras palavras, a redução da desigualdade importa para o combate à corrupção. Em igual sentido, Begović $(2006$, p. 36) ressalta a existência de dois tipos principais de desenhos de pesquisa no que tange à relação entre corrupção e desigualdade. A primeira pauta-se no efeito da corrupção como fator que leva à desigualdade econômica; a segunda analisa a desigualdade econômica como fator explicativo da corrupção. Em qualquer dos casos assume-se que quanto maior a desigualdade maior a corrupção e vice-versa.

No relatório de 2016 a TI expõe a relação entre as pontuações de corrupção no IPC e o grau de exclusão social, como indicam os diagramas a seguir:

Figura 1 - Gráfico Indicador da Relação Entre Exclusão Social e Percepção Acerca da Corrupção (2016)

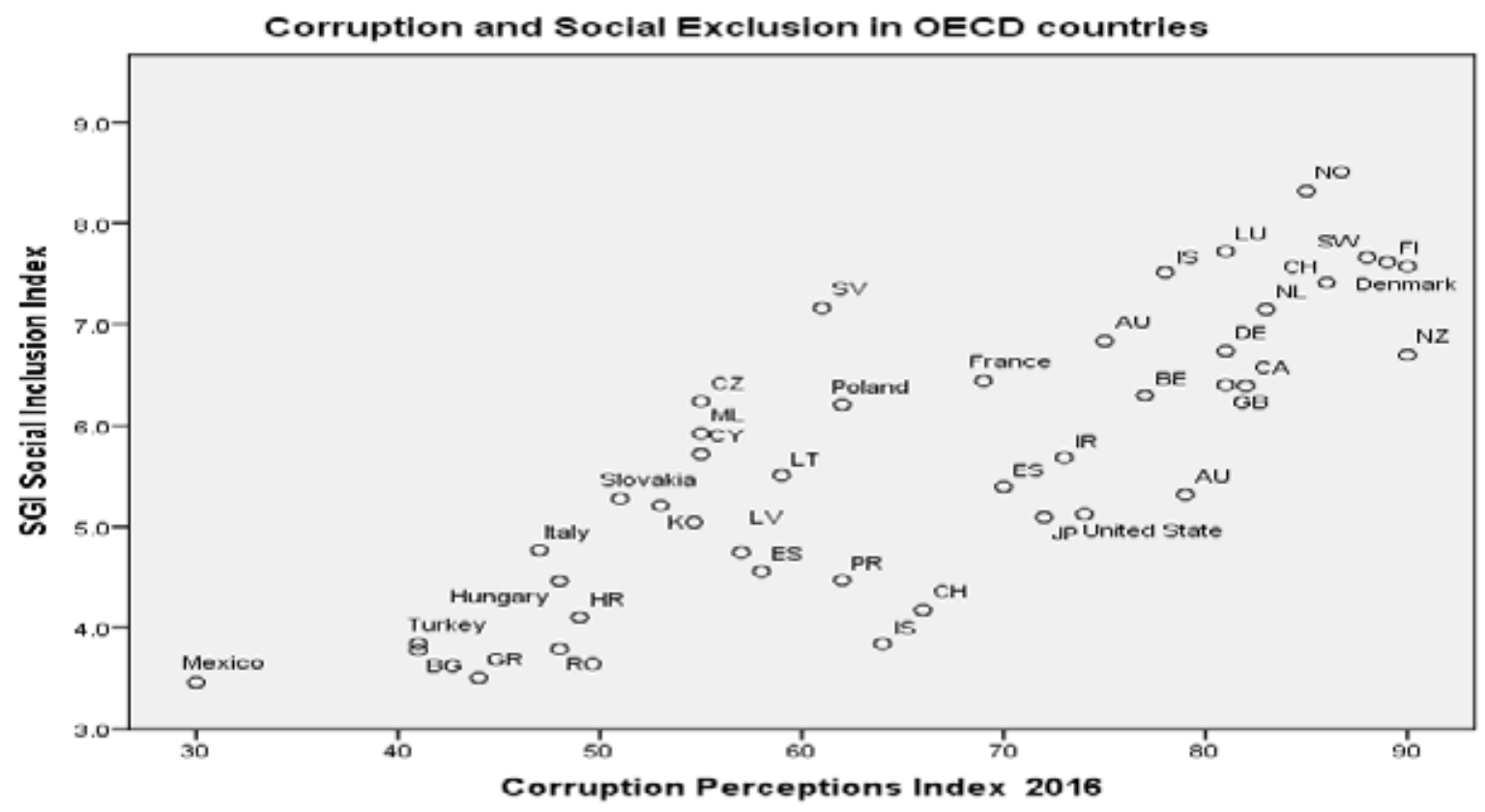

Fonte: TRANSPARENCY INTERNATIONAL, 2016b. 
Observa-se que os resultados mais altos do IPC (CPI, no gráfico) e Inclusão Social (SGI, no gráfico) significam menos corrupção/exclusão. Em sentido contrário, os países que apresentam menores IPC são aqueles dotados de instituições públicas mais frágeis e funcionamento precário. ${ }^{9}$

Destaque-se o México, a Turquia (Turkey) e a Bulgária (BG), que possuem a correlação corrupção/inclusão social em níveis negativos se comparados aos demais países do gráfico. Por outro lado, aqueles que apresentam IPC mais elevado apresentam igualmente grau mais alto de liberdade de imprensa, acesso à informação sobre as despesas públicas, padrões mais fortes de integridade para funcionários públicos e sistemas de justiça independentes, ${ }^{10} \mathrm{com}$ destaque para a Noruega (NO), Luxemburgo (LU), Suíça (SW). Constata-se que quanto menores os índices de exclusão social, maior o IPC.

\subsection{A relação entre IDH e IPC no contexto brasileiro recente}

O IDH brasileiro registrou no ano de 2016 um total de 0,754 pontos, mesmo índice que havia sido registrado em 2014, ocupando o país o 79o lugar no ranking que abrange 188 países. Em 2017, o Brasil se manteve na mesma posição e com o mesmo índice do ano anterior (UNDP, 2016, p. 123).

Figura 2 - Índices de Desenvolvimento Humano no Brasil de 1990 a 2017

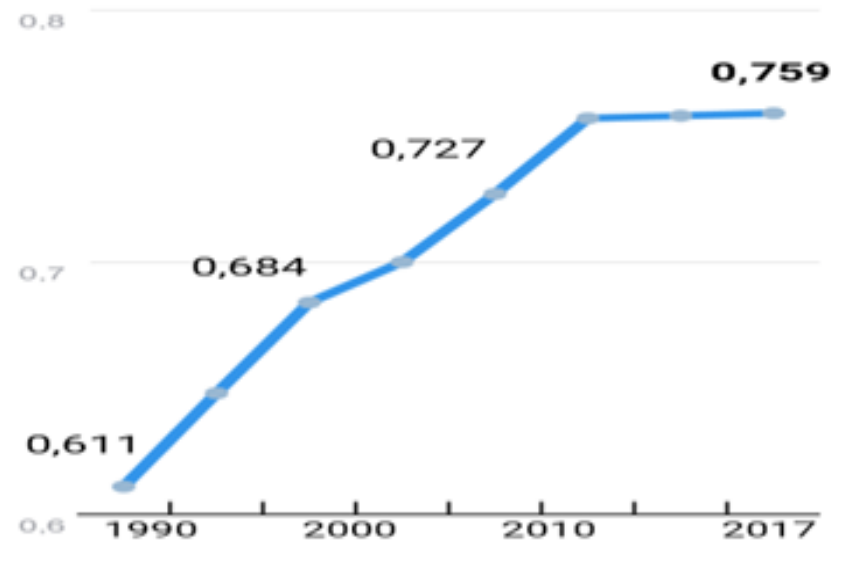

Fonte: VENTURA et al., 2018.

Em termos de IDH, o país permaneceu estagnado pelo terceiro ano consecutivo (UNDP, 2016, p. 256). Desde 2015 o país ocupa a 79a colocação entre 189 países analisados, encerrando um ciclo de evolução. Conforme se observa no gráfico anterior, o Brasil registrava um crescimento do IDH desde 1990, porém estagnou no mesmo patamar a partir de 2014.

\footnotetext{
${ }_{9}$ Para um aprofundamento acerca do assunto, relatório disponível em: http://www.transparency.org/news/feature/ corruption_perceptions_index_2016.

${ }^{10}$ Para uma análise mais detida sobre o assunto, relatório disponível em: http://www.transparency.org/news/feature/ corruption_perceptions_index_2016.
} 


\section{Humanos e \\ Democracia}

De acordo com o Pnud, mais de 29 de milhões de pessoas saíram da pobreza entre 2003 e 2013 (PNUD, 2016, p. 95). O nível de pobreza, entretanto, voltou a crescer entre 2014 e 2015, quando cerca de 4 milhões de pessoas ingressaram em condições de pobreza. Nesse mesmo período, a taxa de desemprego voltou a subir, alcançando mais de 12 milhões de pessoas (PNUD; IPEA, 2016, p. 136).

Apesar de ser a nona maior economia do mundo (FÓRUM..., 2017, p. 25), o Brasil encontra-se entre os países com maior nível de desigualdade de renda, além de elevados níveis de pobreza. De acordo com o Relatório Luz 2018, elaborado pelo Grupo de Trabalho da Sociedade Civil para Agenda 2030 (GTSCA, 2030), ${ }^{11}$ houve um aumento da pobreza e da extrema pobreza. ${ }^{12}$ É o que mostra a figura a seguir:

Figura 3 - Índices de pobreza e extrema pobreza no Brasil nos anos de 1992 a 2017

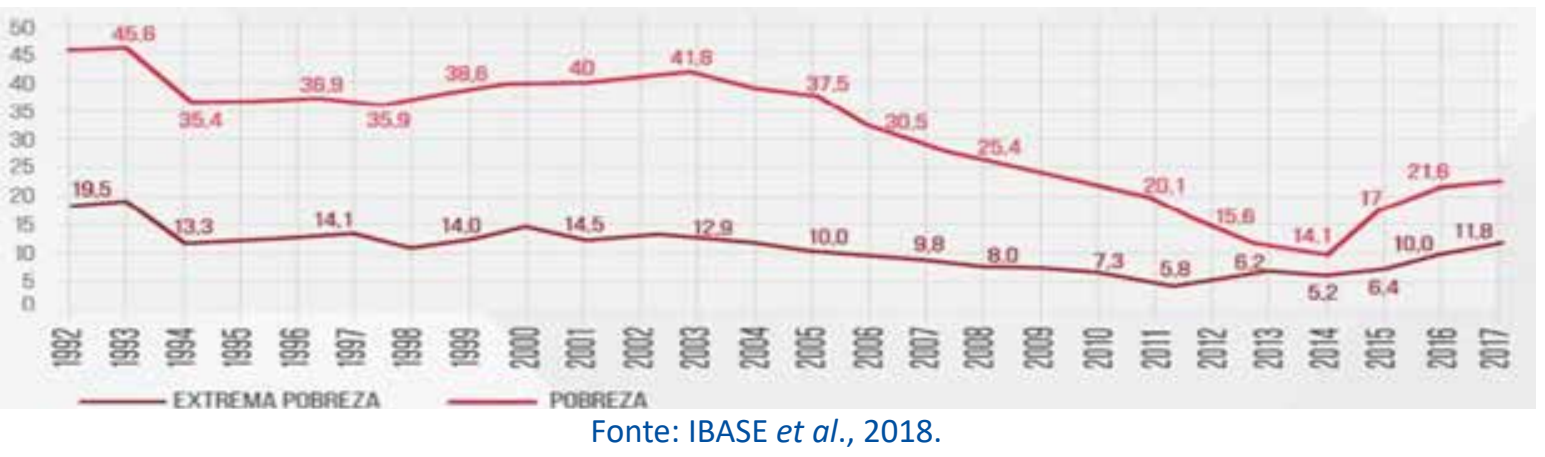

A piora dos índices relacionados ao desenvolvimento podem ser relacionados com o fenômeno da corrupção. Corrupção e desigualdade alimentam-se uma à outra, criando um círculo vicioso entre corrupção, distribuição desigual de poder na sociedade e distribuição desigual de riqueza.

Em estudo realizado pelo FMI constatou-se que o caso de corrupção relacionado a investigações na Petrobras e a crise política afetaram a confiança na economia, tendo um papel-chave no aprofundamento da recessão no Brasil (LIPTON; WERNER; BERKMEN, 2017, p. 12-13). Dessa forma, a interação entre a crise econômica e a crise da política alimentou a incerteza e levou a confiança empresarial e do consumidor a mínimas históricas, minando adicionalmente a atividade econômica atual e futura.

Além de ocasionar um ambiente de instabilidade política, a corrupção vem aumentando os custos para o país na busca pela retomada de recursos no mercado internacional. Dessa forma, torna-se mais caro e dificultoso para as empresas e governos captarem dinheiro no

\footnotetext{
${ }^{11}$ GTSC A2030 é composto por Organizações Não Governamentais, movimentos sociais, fóruns e fundações brasileiras. O grupo foi o resultado do encontro entre organizações que estavam acompanhando a agenda pós-2015 e seus desdobramentos. Inicialmente facilitado pela Abong - Associação Brasileira de ONGs em defesa de direitos e bens comuns - e pela Gestos - Soropositividade, Comunicação e Gênero, o GT foi formalizado em 2014, ainda durante as negociações da Agenda 2030. Desde então tem atuado no segmento da instituição e monitoramento dos Objetivos de Desenvolvimento Sustentável - ODS - focando ainda no acompanhamento da Agenda de Ação de Adis Abeba e buscando alinhar posições com setores progressistas da sociedade civil que seguem a agenda do Clima. O GT tem hoje mais de 40 participantes de diferentes setores e incide sobre o Estado brasileiro e organizações multilaterais, especialmente a Organização das Nações Unidas, visando à garantia e à promoção dos direitos humanos, econômicos, sociais, culturais e ambientais, e a superação das desigualdades.

12 Para mais informações, consultar: http://library.fes.de/pdf-files/bueros/brasilien/14577.pdf
} 
exterior (LIPTON; WERNER; BERKMEN, 2017, p. 33). Há, portanto, custos econômicos diretos da corrupção no Brasil que contribuíram para a instalação da recessão no país, mas também os custos indiretos, vez que índices maiores de corrupção estão atrelados ao maior risco do país, redução dos investimentos produtivos, internos e externos. Ademais, pelo fato de estar associada à redução da eficiência do gasto público, a prática da corrupção repercute negativamente na composição do IDH do país, o qual estagnou no caso brasileiro.

Considerando o IDH e o IPC, a TI aponta em que medida se dá a relação entre o IDH e o IPC:

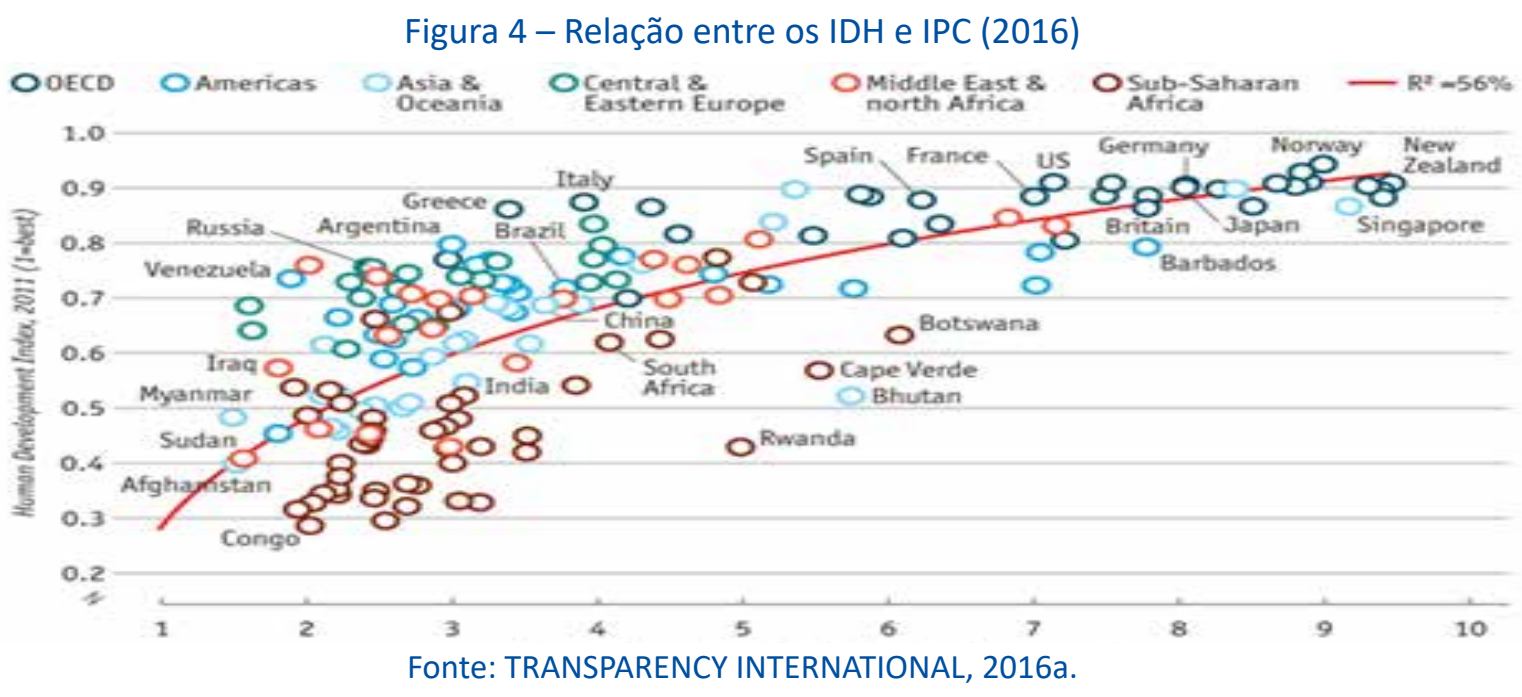

O gráfico assinala que quanto maior o IDH, maior o IPC. Isso porque em países com maior IDH a corrupção é percebida em minúcias, condutas e práticas não entendidas da mesma forma em países com menor IDH, nos quais práticas corruptas tendem a ser mais "toleradas". No ponto alto do gráfico estão países como a Nova Zelândia, Noruega e Singapura, todos com alto IDH e alto IPC. No outro extremo encontram-se países como Afeganistão, Sudão e Congo, todos com baixo IDH e baixo IPC, ou seja, as práticas corruptas não são tão perceptíveis como tal pela população, que tende a tolerar práticas que seriam manifestamente corruptas em outros contextos com maior IDH.

O Brasil situa-se a meio caminho no gráfico, em um quadrante próximo a países como China, África do Sul e Grécia, cuja característica, de modo geral, é de países que possuem IDH médio. Na última avaliação realizada (TRANSPARENCY INTERNATIONAL, 2017, p. 45), no entanto, o Brasil apresentou 37 pontos, ocupando a 96a posição de um total de 180 países, refletindo uma queda de 17 posições no IPC, o que significa que a corrupção deixou de ser tão percebida como antes. No ano anterior (2016), o país possuía 40 pontos e ocupava a 79a posição de um total de 176 países.

A queda do IPC no Brasil faz parte de uma tendência iniciada em 2014, a qual já custou ao país 6 pontos, trazendo a nota de 43 para 37, em uma escala de 0 a 100. Não coincidentemente, nesse período foram desenvolvidas investigações que desvendaram massivos esquemas de corrupção, atingindo as principais lideranças políticas do país, assim como órgãos públicos e empresas estatais. Ao longo de 2017, a imprensa retratou diversos escândalos que surpreenderam o cenário mundial, com a revelação de complexos esquemas de corrupção. 


\section{Humanos e \\ Democracia}

Segundo a organização Transparência Internacional, a queda apresentada pelo Brasil, no que respeita ao seu IPC, é resultado decorrente das investigações, em especial aquelas ligadas ao amplo contexto da Operação Lava Jato, ${ }^{13}$ assim como outras grandes operações que refletem um esforço relevante do país no enfrentamento do problema (SOUZA, 2018).

Tal reflexo ocorre tipicamente nos países que iniciam o combate e o enfrentamento da corrupção e que por consequência acabam por destrinchar todo o problema em todas as suas dimensões. As implicações negativas, entretanto, se revertem, se o país permanece no enfrentamento gerando uma percepção de maior controle da corrupção com o passar do tempo.

No caso brasileiro, o IPC dos últimos anos apresentava uma estabilidade relativa, que conduzia para uma ascensão do índice, no qual o país lograria os esforços empreendidos. A Organização Transparência Internacional, no entanto, interpretou o resultado do Brasil como um país que se encontra no dilema entre prosseguir no enfrentamento da corrupção e assim atingir novas perspectivas ou deixar que as influências que buscam neutralizar o processo de enfrentamento da corrupção persistam e o país continue no caminho da corrupção e impunidade sistêmicas.

Em avaliação da $\mathrm{Tl}$, o resultado negativo que repercute no país decorre do risco que o combate à corrupção possa vir a sofrer. Afirma, igualmente, que essa piora no ranking é resultante da percepção de que os pilares da corrupção nacional seguem intactos, considerando que o Brasil não agiu de forma eficaz no que respeita a estratégias de incidência sistêmica nesse problema (TRANSPARENCY INTERNATIONAL, 2017. p. 21). Destaque-se que o IPC no Brasil caiu nos últimos anos, tendo apresentado uma queda significativa em 2017. Já o IDH manteve-se estagnado de 2014 a 2017.

É viável inferir que o desvio de dinheiro público afeta a oferta de educação e de saúde, e outros serviços necessários para o crescimento do IDH, principalmente da população que mais carece de tais serviços. O relatório global da TI de 2009 (TRANSPARENCY INTERNATIONAL, 2009, p. 75) ressalta que a corrupção não consiste apenas em descaminhos de recursos que seriam revertidos para fins sociais, mas sim em uma redução da governança, que por sua vez pode funcionar como combustível para o crime organizado, assim como redes que promovem crimes como o tráfico de seres humanos, de armas, falsificação e comércio de espécies em perigo.

No Brasil, em relatório anual de 2016, elaborado pelo Ministério da Transparência e pela Controladoria Geral da União, apurou-se que foram 247 operações deflagradas para combater a corrupção, pelo Ministério Público Federal e Polícia Federal no período de 2003 a 2016. Por meio dessas operações identificou-se um prejuízo estimado em 4 (quatro) bilhões de reais (CGU, 2016a, p. 32). As operações de investigação dos crimes de corrupção, a CGU e - Ministério da Transparência apuraram que as principais políticas públicas afetadas pela corrupção, identificadas nessas operações, foram: saúde e educação, conforme a Figura a seguir:

\footnotetext{
${ }^{13}$ A Operação Lava Jato é um conjunto de investigações em andamento pela Polícia Federal do Brasil, que cumpriu mais de mil mandados de busca e apreensão, de prisão temporária, de prisão preventiva e de condução coercitiva, visando a apurar um esquema de lavagem de dinheiro que movimentou bilhões de reais em propinas. A operação teve início em 2014 e conta com 55 fases operacionais. A Polícia Federal a considera a maior investigação de corrupção da história do país.
} 
Figura 5 - Distribuição dos recursos desviados de políticas públicas em decorrência da corrupção. Dados extraídos de investigações policiais da Polícia Federal no Brasil

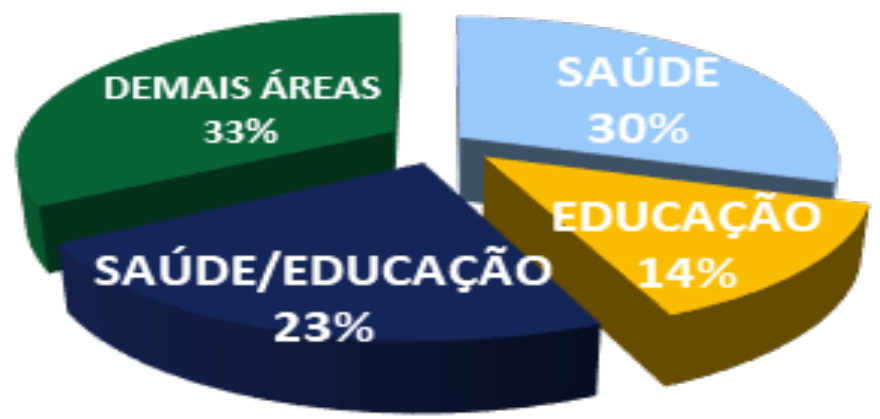

Fonte: CGU; MINISTÉRIO DA TRANSPARÊNCIA, 2016.

Observa-se que os principais recursos públicos afetados pela corrupção são aqueles imprescindíveis para a promoção de um desenvolvimento no país. Ambos os fenômenos, corrupção e desenvolvimento, interagem em um círculo vicioso: a corrupção leva a uma distribuição desigual do poder na sociedade, que, por sua vez, se traduz em uma distribuição desigual de riqueza e oportunidade.

\section{CONSIDERAÇÕES FINAIS}

A orientação para promover o desenvolvimento como objeto central dos esforços internacionais foi decisiva para a mudança de concepção em torno da corrupção, expandindo-se a tradicional visão de tolerância sobre a prática, que considerava seus efeitos como restritos aos ambientes dos negócios e transações econômicas. O novo enfoque passa a considerá-la como fenômeno que cerceia prerrogativas necessárias ao exercício dos direitos humanos e da promoção do desenvolvimento e por isso a ser combatido e superado.

A abordagem ampliada do desenvolvimento trazido pelas formulações internacionais, especialmente no âmbito destas sobre o direito ao desenvolvimento, parece ter sido decisiva nessa mudança de concepção em torno das causas e consequências da corrupção, bem como para a formulação de nova normativa internacional que orienta os Estados nas medidas de combate à corrupção, por ser norma necessária à promoção do desenvolvimento global.

A relação entre desenvolvimento, direitos humanos e corrupção revela-se, assim, fecunda, posto que ao complexificar a análise sobre a corrupção, consegue oferecer respostas à altura do desafio, especialmente nos contextos nacionais em que a prática da corrupção é sistêmica. Nesses contextos há uma redução da capacidade do Estado para desempenhar suas funções básicas, especialmente na promoção do desenvolvimento e dos direitos humanos, uma vez que a corrupção se caracteriza justamente como força contrária à correta alocação dos recursos públicos destinados a este fim.

Se, entretanto, por um lado o irromper global do discurso anticorrupção gerou um ambiente internacional de expressivo combate à prática, gerou também controvérsias a respeito da validade do uso acrítico destas medidas, haja vista que a experiência histórica revela seu uso como estratégia de deslegitimação de governos ou Estados. O efeito colateral parece afetar em alguma medida o ambiente institucional necessário à promoção dos direitos humanos 


\section{Humanos e \\ Democracia}

e à efetivação do direito ao desenvolvimento. No caso brasileiro, o ambiente de combate à corrupção e a crise política e econômica instalados apontam para um contexto empírico repleto de evidências sobre a relação entre desenvolvimento, direitos humanos e corrupção.

\section{REFERÊNCIAS}

AL-MARHUBI, Fahima. Corruption and inflation. Economics Letters, Nova York. v. 66, n. 2, p. 199-202, 2000. Disponível em: http://www.cgu.gov.br/sobre/institucional/eventos/anos-anteriores/2016/. Acesso em: 10 jun. 2017.

BACIO-TERRACINO, Julio. Linking Corruption and Human Rights. Proceedings of the Annual Meeting. American Society of International Law. Washington, v. 104, p. 58-74, Jan./June 2010.

BEGOVIĆ, Boris. Economic inequality and corruption. In: Third World Bank conference onine quality, "Inequality, Politics and Power". Washington: The World Bank. 2006. Disponível em: http://danica.popovic.ekof.bg.ac. rs/206.pdf 2006. Acesso em: 15 jul. 2017.

CGU. Controladoria Geral da União. Relatório de gestão - exercício 2016a. Disponível em: http://www.agu.gov. br/page/content/detail/id_conteudo/74700. Acesso em: 10 jun. 2017.

CGU. Controladoria Geral da União. Dia Internacional Contra a Corrupção. 2016b. Disponível em: http://www. cgu.gov.br/sobre/institucional/eventos/anos-anteriores/2016/. Acesso em: 30 maio 2018.

DOIG, Alan; RILEY, Stephen. Corruption and Anti-Corruption Strategies: Issues and case studies from developing countries. Disponível em: http://www.undp.org/oslocentre/PAR_Bergen_2002/corruption.htm\#3 Corruption and Anti-Corruption. Acesso em: 20 jun. 2017.

FILGUEIRAS, Fernando de Barros. Notas críticas sobre o conceito de corrupção: um debate com juristas, sociólogos e economistas. Revista de Informação Legislativa. Brasília. v. 41, n. 164. p. 89-100, out./dez. 2004.

FÓRUM ECONÔMICO MUNDIAL. Las 10 mayores economías del mundo en 2017. 2017. Disponível em: https:// es.weforum.org/agenda/2017/03/las-10-mayores-economias-del-mundo-en-2017/. Acesso em: 2 out 2018.

FRANCO, F. C. O direito ao desenvolvimento como resultado do encontro entre direitos humanos e desenvolvimento. In: FEITOSA, M. L.et al. Direitos humanos de solidariedade: avanços e impasses. 2. ed. Curitiba: Editora Appris, 2013.

GEBEYE, Berihun Adugna. Corruption and Human Rights: exploring the relationship. Etiópia. 2012. Disponível em: http://www.du.edu/korbel/hrhw/workingpapers/2012/70-gebeye-2012.pdf. Acesso em: 4 abr. 2018.

GUPTA, S. et al. Does corruption affect income inequality and poverty? Economics of Governance, Springer, v. 3, n. 1. p. 23-45, Oct./Dec. 2002. Disponível em: http://repositorio.ufpe.br/bitstream/handle/123456789/12549/ DISSERTA\%C3\%87\%C3\%830\%20Flavius\%20Raymundo\%20Arruda\%20Sodre.pdf?sequence=1\&isAllowed=y. Acesso em: 12 dez. 2018.

JAIN, Arvind K. Corruption: a Review. Journal of Economics Surveys, New Jersey. v. 15, n. 1, Nov./Dec. 2001.

KAUFMANN, Daniel; PRAHAN, Sanjan; RYTERMAN, Randi. New frontiers in diagnosing and combating corruption. New York: The Worlds Bank Prem. Notes, n. 7, Oct. 1998.

KOECHLIN, Lucy; CARMONA, Magdalena Sepúlveda. In: ROTBERG, Robert I. Corruption, global security and world order. Washington D.C.: Brookings Institution Press, 2009.

KUMAR, C. R. Corruption and Human Rights: Promoting Transparency in Governance and the Fundamental Right to Corruption-Free Service in India. Columbia Journal of Asian Law. v. 17, n. 1, Apr./May 2003.

LIPTON, David; WERNER, Alexandre; BERKMEN, S. Pelin. Fundo Monetário Internacional (FMI). Corrupção na América Latina: um caminho para o futuro. 2017. Disponível em: https://www.imf.org/external/lang/portuguese/np/blog/2017/092817p.pdf. Acesso em: 2 out. 2018.

MAURO, Paolo. Os efeitos da corrupção sobre crescimento, investimentos e gastos do governo: uma análise de países representativos. In: ELLIOTT, Kimberly Ann (org.). A corrupção e a economia global. Brasília: Universidade de Brasília, 2002.

PNUD; IPEA. Programa das Nações Unidas para o Desenvolvimento; Instituto de Pesquisa Econômica Aplicada. Relatório do Radar IDHM. 2016. Disponível em: http://www.atlasbrasil.org.br/2013/data/rawData/RadarIDHM_ VERSAO_Final.pdf. Acesso em: 30 set. 2018.

PNUD. Programa das Nações Unidas para o Desenvolvimento. Relatório de Desenvolvimento Humano Regional para a América Latina e o Caribe 2016. 2016. Disponível em: http://www.br.undp.org/content/dam/brazil/ docs/IDH/undp-br-progresso-multidimensional-2016.pdf. Acesso em: 30 set. 2018. 
RAJAGOPAL, Balakrishnan. Corruption, Legitimacy and Human Rights: The dialetic of the relationship. Connecticut Journal of International Law, v. 14, n. 4. p. 495-510, June/July 1999.

SOUZA, Ludmila. Índice de percepção da corrupção no Brasil tem queda e país fica pior no ranking. Agência Brasil. São Paulo, 21 fev. 2018. Disponível em: http://agenciabrasil.ebc.com.br/geral/noticia/2018-02/indice-de-percepcao-da-corrupcao-no-brasil-tem-queda-e-pais-fica-pior-no. Acesso em: 29 set. 2018.

SPECK, Bruno Wilhelm. Mensurando a corrupção: uma revisão de dados provenientes de pesquisas empíricas. Rio de Janeiro. Cadernos Adenauer, v. 10, p. 9-45, mar./maio 2000.

TANZI, Vito; DAVOODI, Hamid. Corruption, Public Investment, and Growth. Corruption, Public Investment, and Growth, v. 97, n. 139, p. 89-120, out./dez. 1997.

TRANSPARENCY INTERNATIONAL. Corruption Perceptions Index 2009. 2009. Disponível em: https://www.transparency.org/whatwedo/publication/relatorio_global_de_corrupcaeo_2009_corrupcaeo_e_o_setor_privado. Acesso em: 3 maio 2018.

TRANSPARENCY INTERNATIONAL. Índice de percepção da corrupção 2016: círculo vicioso de corrupção e desigualdade deve ser rompido. 2016a. Disponível em: https://www.transparency.org/news/pressrelease/indice_ de_percepcaeo_da_corrupcaeo_2016_circulo_vicioso_de_corrupcaeo. Acesso em: 17 jun. 2017.

TRANSPARENCY INTERNATIONAL. Corruption Perceptions Index 2016. 2016b. Disponível em: https://www.transparency.org/news/feature/corruption_perceptions_index_2016. Acesso em: 3 out. 2017.

TRANSPARENCY INTERNATIONAL. CORRUPTION PERCEPTIONS INDEX 2017. 2017. Disponível em: https://www. transparency.org/news/feature/corruption_perceptions_index_2017. Acesso em: 3 abr. 2018.

UNDP. United Nations Development Program. 2011. Relatório de desenvolvimento humano 2011. 2011. Disponível em: http://hdr.undp.org/sites/default/files/reports/271/hdr_2011_en_complete.pdf. Acesso em: 15 jul. 2018.

UNDP. United Nations Development Program. Relatório de desenvolvimento humano 2015. 2015. Disponível em: http://www.br.undp.org/content/brazil/pt/home/idh0/relatorios-de-desenvolvimento-humano/rdhs-globais. html\#2016. Acesso em: 27 set. 2018.

UNDP. United Nations Development Program. Relatório de desenvolvimento humano 2016. 2016. Disponível em: http://www.br.undp.org/content/dam/brazil/docs/RelatoriosDesenvolvimento/undp-br-2016-human-development-report-2017.pdf. Acesso em: 28 set. 2018.

VENTURA, Manoel et al. IDH: educação não avança e Brasil fica estagnado no ranking de bem estar da ONU. $O$ GLOBO. 2018. Disponível em: https://oglobo.globo.com/economia/idh-educacao-nao-avanca-brasil-fica-estagnado-no-ranking-de-bem-estar-da-onu-23067716\#: :text=A\%20taxa\%20de\%20crescimento\%20do,de\%20estudo\%20subiu\%204\%20anos.

VIEIRA, Gabriela Alves Mendes; VARELLA, Marcelo Dias. A conexão entre os direitos humanos e a corrupção. Revista de Direito Internacional. v. 12, n. 2, p. 35-57, 2014. ISSN 22371036.

YOU, J. S.; KHAGRAM, S. A. Comparative Study of Inequality and Corruption. American Journal Association, v. 70, n. 1, Feb. 2005.

WORLD BANK. Helping countries combat corruption: the role of the World Bank. Washington: World Bank, 2000. 